\title{
Anti-ss DNA Antibody
}

National Cancer Institute

\section{Source}

National Cancer Institute. Anti-ss DNA Antibody. NCI Thesaurus. Code C114567.

A type of antinuclear antibody that specifically targ ets single stranded (denatured) DNA; these antibodies are often detectable in multiple different autoimmune and rheumatologic disorders, but their presence is neither sensitive nor specific to diagnosing any one of these diseases. 